\title{
A estratégia top-down da política pública de agricultura familiar na Guiné-Bissau
}

\author{
Marcelino Armindo Monteiro \\ Universidade Estadual do Oeste do Paraná (PGDRA/UNIOESTE) \\ Zelimar Soares Bidarra \\ Programa de Pós-Graduação em Desenvolvimento Regional e Agronegócio / Universidade Estadual do Oeste \\ do Paraná (PGDRA/UNIOESTE) \\ Moacir Piffer \\ Programa de Pós-Graduação em Desenvolvimento Regional e Agronegócio / Universidade Estadual do Oeste \\ do Paraná (PGDRA/UNIOESTE)
}

Recebido: 13/05/2017 Versão revisada (entregue): 01/04/2020 Aprovado: 19/05/2020

\begin{abstract}
Resumo
O objetivo deste artigo é analisar, no âmbito teórico, os resultados do Projeto de Apoio à Segurança Alimentar (PASA) nas regiões onde atua (Biombo, Gabu e Tombali) na sua primeira fase, nos períodos de 2010-2015, na República da Guiné-Bissau, África Ocidental. Sua construção baseou-se nas informações oriundas dos relatórios anuais das atividades do PASA e a metodologia aplicada foi a de estudo qualitativo exploratório, com base em pesquisa bibliográfica e documental. Das atividades planejadas na primeira fase do PASA, foram implementadas as seguintes: a recuperação dos campos de produção de arroz de mangrove e de várzeas que anteriormente foram afetadas pela salinidade; oportunidade de fornecimento de crédito; formação técnica dos gestores das associações; e o alto incremento da produção de arroz. A análise evidencia que a política pública implementada foi efetivada como top-down, e que o PASA, pelos seus moldes, igualmente goza destas características, pois as ações são pensadas e implementadas por consultores contratados pelo financiador, a União Econômica e Monetária da África Ocidental, e pelo governo da Guiné-Bissau, sem espaço para uma participação mais efetiva da parte local das três regiões beneficiadas.
\end{abstract}

Palavras-chave | Desenvolvimento rural; Guiné-Bissau; participação social; políticas públicas; segurança alimentar.

Código JEL | O13 Q13 R58

The top-down strategy of the family farming public policy in Guinea-Bissau

\section{Abstract}

The objective of this article is to analyze, in theoretical terms, the results of the Food Security 
Support Project (PASA) in the regions where it operates (Biombo, Gabu and Tombali) in its first phase (2010-2015), in the Republic of Guinea- Bissau, West Africa. Its construction was based on information from the annual reports of PASA activities, and the applied methodology was a qualitative exploratory study, based on bibliographic and documentary research. Among all the activities planned in the first phase of PASA, the following were implemented: the recovery of mangrove and lowland rice production fields that were previously affected by salinity; opportunity to provide credit; technical training of the association managers and the high increase in rice production. The analysis shows that the implementation of the public policy was carried out as a top-down policy, and that PASA, due to its molds, also enjoys these characteristics. Since the actions are designed and implemented by consultants hired by a financier, the Economic and Monetary Union of Africa, and the government of Guinea-Bissau, there is no room for effective local actors' participation in the three benefited regions.

Keywords | Food security; Guinea-Bissau; public policy; rural development; social participation.

JEL-Code | O13 Q13 R58

\section{La estrategia top-down de la política pública de la agricultura familiar en Guinea- Bissau}

\section{Resumen}

El objetivo de este artículo es analizar, en el contexto teórico, los resultados del Proyecto de Apoyo a la Seguridad Alimentaria (PASA) en las regiones donde opera (Biombo, Gabu y Tombali) en su primera fase, en los períodos 2010-2015, en la República de Guinea -Bissau África Occidental. Su construcción se basó en informaciones provenientes de los informes anuales de actividades de PASA y la metodología aplicada fue la de un estudio exploratorio cualitativo, basado en investigación bibliográfica y documental. De las actividades planificadas en la primera fase de PASA, se implementaron las siguientes: la recuperación de los campos de producción de arroz de manglares y llanuras aluviales que anteriormente estaban afectados por la salinidad; oportunidad de proporcionar crédito; capacitación técnica de los gerentes de las asociaciones; y el alto aumento de la producción de arroz. El análisis muestra que la política pública se implementó de arriba hacia abajo, y que PASA, de manera similar, también disfruta de estas características, pues las acciones son pensadas e implementadas por consultores contratados por el financiador, la Unión Económica y Monetaria de África Occidental, y por el gobierno de Guinea-Bissau, sin espacio para una participación más efectiva de la parte local de las tres regiones beneficiadas.

Palabras clave | Desarrollo rural; Guinea-Bissau; participación social; políticas públicas; seguridad alimentaria.

Codigo JEL | O13 Q13 R58 


\section{Introdução}

Os países africanos, em particular aqueles localizados na África Ocidental, estão empenhados em desenvolver projetos que alargam apoio à soberania alimentar. Esta preocupação pode ser determinada, por exemplo, quando verifica-se que a maioria das explorações familiares africanas não produzem grãos suficientes para própria alimentação e deve-se comprar no mercado para colmatar o déficit, que de grosso modo são grãos importados do exterior (BARON, 2006; APESS, 2013; BIVAR; TEMUDO, 2014).

Antes de seguir com a discussão, vale esclarecer para o leitor o nosso entendimento, ou seja, até o momento o que se entende como segurança alimentar e soberania alimentar na África em geral e, em particular, na África Ocidental e, por fim, no Brasil. Na África Ocidental, 60\% da população - o equivalente a 175 milhões de pessoas -, segundo dados da Comunidade Econômica dos Estados da África Ocidental (Cedeao), vivem com menos de um dólar por dia. Para esta comunidade, a segurança alimentar significa que todos os cidadãos destes países tenham acesso suficiente e constante de alimentos. Por outro lado, a soberania alimentar é para estes países produzirem alimento suficiente para suas populações, sem se recorrer, ou se possível o mínimo, à importação dos alimentos produzidos no exterior (ECONOMIC COMMUNITY OF WEST AFRICAN STATES, 2008).

É uma visão simples, mas que se justifica se comparada com a discussão atual nos países desenvolvidos, principalmente nos europeus, bem como em alguns da América Latina. Neste último caso também se aborda a discussão de maneira diferente.

No Brasil, o conceito de segurança alimentar está avançado na sua formulação e também há divergência no seu uso dependendo da visão e da área em que será aplicada o conceito. Sendo um país "avançado", neste quesito se comparado com os países da África Ocidental, o conceito de segurança alimentar usado é mais aprofundado. Neste caso, vamos nos ater ao conceito brasileiro de segurança alimentar usado por Belik (2010) e depois empregado no trabalho dos autores Vendramini, Oliveira e Campi (2012): a segurança alimentar e nutricional consiste na realização do direito de todos ao acesso regular e permanente a alimentos de qualidade. Ainda, em quantidade suficiente, sem comprometer o suprimento de outras necessidades essenciais, tendo como base práticas alimentares promotoras da saúde que respeitem a diversidade cultural e que sejam ambiental, cultural, econômica e socialmente sustentáveis.

O conceito em uso no Brasil tem mais um olhar na qualidade do alimento e fortemente acentuadas as questões ambientais, que aponta nos dilemas da sustentabilidade. Por outro lado, ao observamos o conceito nos países da África 
Ocidental, consegue-se perceber as questões do acesso ao alimento para todos integralmente, o maior em acesso como ato mais evocado.

Os autores ainda afirmam que a segurança alimentar é alcançada quando todas as pessoas têm acesso físico e econômico a alimentos (VENDRAMINI; OLIVEIRA; CAMPI, 2012). E assim, a soberania alimentar consiste no direito de cada país, de certa forma, produzir os seus próprios alimentos e consumi-los conforme os seus hábitos, cultura e tradições (BELIK, 2010).

$\mathrm{Na}$ prática, as oscilações dos preços dos produtos agrícolas, em especial, commodities, podem tornar a situação difícil para aqueles que destinam parte importante da sua renda para a compra de alimento. Neste particular, a decadência dos países da África Ocidental em relação à produção e distribuição dos produtos nos mercados de bens alimentares apresenta-se como um grande problema. $\mathrm{O}$ debate sobre segurança, assim como a soberania alimentar, torna-se inevitável. Os países em desenvolvimento, principalmente os do continente africano, devem se debruçar neste debate. Como afirma Belik (2010), a soberania alimentar colocou a questão das relações de poder entre países e da autonomia das populações no sentido de poderem escolher a sua dieta de acordo com os seus hábitos sociais e a sua cultura. O mesmo autor define a segurança alimentar como elemento fundamental de Política Pública, dando ênfase às caraterísticas quantitativas e qualitativas desse suprimento.

Portanto, Araújo (2007) define o foodsafety e o foodsecurity. O primeiro conceito, é a garantia de que um alimento não causará danos ao consumidor por meio de perigo biológico, químico ou físico. Já o segundo termo enfatiza que todas as pessoas, a qualquer momento, tenham a garantia do acesso físico, social e econômico a alimentos suficientes, seguros e nutritivos, que sustentem uma vida ativa e saudável. Para os países da África Ocidental, e em particular a Guiné-Bissau, os esforços para garantir o cumprimento destes objetivos ainda se mostra distante devido à situação histórica e econômica em que se encontra no momento.

Mas a prioridade poderia ser, no princípio, a produção suficiente de alimento que garanta a soberania alimentar e, depois, pensar na segurança alimentar. Neste sentido, o artigo tem como seu objetivo analisar no âmbito teórico os efeitos do Projeto de Apoio à Segurança Alimentar (Pasa) nas regiões de Biombo, Gabu e Tombali em Guiné-Bissau, durante a sua primeira fase de implantação, de 2010 a 2015. O problema que motivou este estudo parte de seguinte questionamento: o Pasa conseguirá cumprir seus objetivos seguindo o mesmo formato aplicado pelos projetos anteriores?

Para elaboração deste artigo, baseou-se nas informações dos relatórios anuais das atividades do projeto Pasa. A metodologia aplicada é a qualitativa com base no estudo bibliográfico e documental do projeto e do Ministério da Agricultura da Guiné-Bissau. Gil (2008), considera pesquisa como processo formal e sistemático de desenvolvimento do método científico. Para o autor, a pesquisa bibliográfica é 
desenvolvida a partir de material já elaborado, constituído principalmente de livros e artigos científicos.

Igualmente, o estudo terá como seu objeto as três regiões: Biombo, Gabu e Tombali, que serão analisadas separadamente nos pontos 3.1 e 3.2, respectivamente. $\mathrm{O}$ artigo foi dividido em quatro partes incluindo esta introdução. A segunda parte debruçou-se no debate teórico sobre as políticas públicas e as estratégias de top-down ${ }^{1}$; a terceira centrou-se na análise da agricultura familiar e os impactos do projeto Pasa; e a quarta são as considerações finais do trabalho.

\section{Debate teórico sobre as políticas públicas}

Os executores das políticas públicas atuam de maneira consciente para proteger o interesse dos grupos aos quais pertencem. As discussões sobre as políticas públicas elaboradas por diferentes pensadores deixam evidente como as políticas públicas são desenhadas e alinhadas especificamente com interesses dos grupos que as delinearam. A importância de estudar estes "artifícios" (public policy) iniciouse no continente europeu e seguiu para os Estados Unidos de América e depois se dispersou pelo mundo.

\section{Decisôes e conflitos de policy makers}

A área que estuda a política pública (public policy) surgiu no velho continente (Europa) como desdobramento dos trabalhos baseados em teorias sobre papel do Estado e do governo, este último como produtor por excelência. Assim, Souza (2006) acrescenta, ainda, que nos Estados Unidos da América a área surge de maneira diferente da Europa. No mundo acadêmico não existe uma ligação nas bases teóricas do papel do Estado, mas, sim, uma ênfase sobre estudos das ações dos governos. Sendo assim, segundo Pereira (2008), a Policy Science não tem como objeto de estudo a estrutura do governo ou comportamento dos atores políticos, o que podem ou não fazer. Mas, sim o objetivo principal é encontrar o resultado, o que um político realmente desenvolve durante o exercício do poder, num período do seu mandato.

Segundo Souza (2006), a política pública é um campo de conhecimento que tanto pode incidir sobre o governo em ação ou analisar esta, quanto à mudança de rumo, bem como de percurso. Neste caso, afirma a autora, a formulação destas políticas públicas se estabelece num estágio onde os governos democráticos

\footnotetext{
${ }^{1}$ Najam (1995) considera o modelo top-down como o tipo dominante, o qual se inicia na tomada de decisão das autoridades ou dos executores da política. As decisões são tomadas do alto nível do governo e direcionadas para baixo, deferente de botton-up (iniciativa local).
} 
traduzem propósitos e plataformas eleitorais em programas e ações que produzem resultados e mudanças no mundo real. Portanto, após a formulação, desdobram-se em planos, programas, projetos, base de dados e informações para pesquisa.

Num olhar diferente da Souza (2006), Fonseca (2013) argumenta que alguns dos pesquisadores e governantes conceituam ou divulgam de maneira linear o conceito da política pública. Os autores entendem que existe difusão sem critério da expressão e qualquer ação governamental, mesmo as atividades elementares do governo são associadas às políticas públicas.

Nesta mesma linha há um entendimento de que a política pública não significa só ação como pode ser também a não ação (inação). A ideia da não ação é pelo fato de estar relacionada a conflitos de interesses, o que exige a visão de administrar melhor esses problemas. Tratando-se de uma estratégia de ação pensada, planejada e avaliada, ligada a uma racionalidade do grupo, onde o Estado e a sociedade desempenham papeis ativos. A política pública implica, simultaneamente, na intervenção do Estado, incluindo diferentes atores por meio da demanda ou pelo controle democrático (PEREIRA, 2008).

Para Fonseca (2013), pode ser assinalada a política pública como um processo de decisão política a ser materializada em objetos, com resultados almejáveis, ligada à mudança de uma realidade por meios distintos. O que Pereira (2008) considera como uma visão parcial e pragmática, visto que ela também contempla demandas sociais e comporta as correlações de forças.

A ideia da política pública consensual e generosa omite o que realmente acontece no mundo real, isto é: os embates entre as forças e os conflitos que se expressam em diversas etapas. Fonseca (2013) demonstra que na prática as políticas públicas espelham, de certa forma, intermináveis teias de interesses que envolvem disputa do poder que implica necessariamente em conflitos.

Para melhor compreensão sobre a existência destes conflitos, Pereira (2008), apresentou quatro arenas de disputas: regulamentadora, redistributiva, distributiva e constitutiva. Segundo a autora, a arena redistributiva decorre das políticas de caráter de "jogo de somo zero", ou seja, numa situação na qual um grupo ganha, outro terá que perder. Estas políticas, segundo Souza (2006), atingem a um maior número de pessoas e impõem, num determinado período de tempo, perdas a determinados grupos sociais, e benefícios incertos para outros. Assim, cada uma destas arenas suscita nos grupos atitudes de vetos e de apoios diferentes.

Monteiro (2008, p. 1238) confirma que a questão maior está nas escolhas feitas pelas elites dirigentes (policy makers) que, em larga escala, só atendem aos interesses da minoria que, com o tempo, leva a grandes crises econômicas. "De fato, as escolhas públicas são amplamente arquitetadas e operacionalizadas pela via da deliberação da alta gerência do executivo". É ampla a extensão que uma política pública pode incorporar, como os critérios de decisão informal que atenda as preferências dos burocratas, de forma despercebida pelo público como imprópria. 


\section{O modelo de formulação top-down e participação coletiva}

A discussão sobre políticas públicas ocorre em diferentes frentes. Há autores, como Van Meter e Van Horn (1975), Edwards (1980), Mazmania e Sabatier (1983), Linder e Peter (1987), e Najam (1995), que consideram que as políticas públicas funcionam como um meio de solucionar problemas relativos ao embate ideológico e ao jogo de poder. E este jogo seria em alguns casos mediante a forma de imposição das ideias de "cima para baixo" (top-down). Najam (1995) considera o modelo top-down como o tipo dominante, o qual se inicia na tomada de decisão das autoridades ou dos executores da política. As decisões são tomadas do alto nível do governo e direcionadas para baixo, deferente de botton-up (iniciativa local).

O esforço para entender o que os governantes fazem ou como eles atuam para implementarem os projetos que melhoram a situação socioeconômico da população e tornar acessível os instrumentos que permitem o desenvolvimento dos países, leva os pesquisadores a discutirem as formas e os objetivos da implementação de determinadas políticas públicas (CARVALHO; BARBOSA; SOARES, 2010).

Carvalho, Barbosa e Soares (2010) afirmam que o sucesso da implementação, de certa forma, está ligado à direção top-down ou botton-up, considerando o tipo de política e o ambiente em que o projeto é implementado. Para eles, além do fator de direcionamento, existem outros, como as características do processo de negociação, a natureza do foco da política, as particularidades das equipes, as condições políticas, econômicas e sociais etc. Os autores consideram que existe uma divergência entre os dois modelos (top-down e botton-up) quanto às abordagens. A do tipo top-down apresenta a decisão política de forma autoritária definida do nível central, enquanto a do botton-up considera as complexidades dos processos da execução, a diversidade dos atores e do espaço.

Com base nessa divergência, pesquisadores debatem a eficiência dos formatos escolhidos pelos governos (ou dos executores dos projetos). O trabalho de Najam (1995) sumariza as várias visões e modelos. O modelo de Van Meter e Van Horn (1975) considera três causas que levam ao insucesso de uma perspectiva de implementação do projeto top-down, sendo elas: quando os subordinados não sabem o que seus superiores querem, eles não conseguem ou se recusam a fazer o que seus líderes desejam.

Essas causas, segundo os autores, são afetadas pelas seguintes variáveis: (1) a relevância dos objetivos políticos, (2) as políticas dos recursos, (3) a comunicação interorganizacional e as atividades, (4) as características das agências de implementação, (5) os ambientes econômicos, sociais e políticos que afetam as normas e organizações executoras, e (6) a disposição dos executores em aceitarem as decisões políticas. 
O modelo de Edwards (1980), segundo Najam (1995), tenta responder as seguintes questões: quais são as precondições para uma política pública seja bemsucedida na sua implementação? E quais sãs os obstáculos iniciais que impedem o sucesso na implementação das políticas públicas? Para isso, identificou quatro fatores de interação e de operação neste processo: (1) a comunicação (a sua importância no processo), (2) os recursos (o uso eficiente e consciente), (3) a disposição (o empenho dos executores em todas as etapas) e (4) a estrutura burocrática (o fluxo das ações do governo ou da entidade executora).

O modelo que Najam (1995) considera como o mais influente na perspectiva topdown é o de Mazmanian e Sabatier (1983), neste caso, os autores avaliam que: (1) a atividade política é um processo interativo de formulação, implementação e reformulação, ao mesmo tempo em que se nota a necessidade da escolha de uma entre as três condições, (2) a necessidade de manter o foco nos objetivos da política do Estado e, também, nos benefícios das agências de implementação e as exigências do processo da implementação do projeto, (3) a visão do processo da implementação deve ser direcionadas em três perspectivas: no centro (policymaker) ou executores da política; no nível inicial da implementação, os oficiais de nível do campo ou da periferia; e, por fim, os atores, para os quais os programas são destinados ou afetados direta ou indiretamente.

Assim, o sucesso inclui três categorias, segundo Najam (1995): a flexibilidade dos problemas, a habilidade na tomada das decisões na estrutura da execução e a consideração das variáveis não-estatutárias que afetam a implementação. O modelo top-down não considera, ou se o faz é de maneira reduzida, a questão da participação social no processo da implementação dos projetos, destinados a uma determinada região. No entanto, é intensa, pertinente e decisiva a discussão teórica sobre as formas de participação social no processo de desenvolvimento regional.

A participação supõe uma relação de poder entre os atores, estabelecendo determinados procedimentos e comportamentos racionais. Teixeira (2001) distingue entre a participação orientada para a decisão e a participação orientada para a expressão. A primeira está voltada para decisão, caracteriza-se pela intervenção de forma organizada, incluindo atores da sociedade civil no processo decisório. A segunda tem foco na expressão e caracteriza-se pela sua intensa presença na cena política com influência no processo decisório. O conceito da participação social é aqui entendido como um processo não simétrico e complexo entre o Estado a sociedade civil e o mercado, por meio dos papeis redefinidos para o fortalecimento da sociedade civil, pela atuação organizada das pessoas.

Os autores entendem que as formas da participação se reúnem em torno de projetos produtivos e de proteção dos serviços básicos, com apoio das organizações não-governamentais (ONGs), tal como nos exemplos dos Comitês de Desenvolvimento de Bairros em Abidjan (Costa do Marfim) que se ocupam com a realização de trabalhos ligados aos equipamentos públicos (iluminação e 
alfabetização) e da Federação Sul-Africana dos Sem-Teto, que constrói casas a baixo custo para a população mais pobre (TEIXEIRA, 2001; DRECHSEL at al., 2008).

Estes fatos, podem ser consideradas como a participação orientada para a decisão. Fato similar tem acontecido na Guiné-Bissau, como no exemplo de Ação para Desenvolvimento (AD) em Bissau, que trabalha com comunicação comunitária, com formação profissional e com microcrédito. Assim como a Tininguena, que atua nos projetos de desenvolvimento local nas áreas de agricultura e proteção ambiental. Neste último, suas ações ocasionam forte influência na tomada de decisão pública na área ambiental e pode ser considerada como uma participação orientada para a expressão. Estas ações, acendem oportunidades para que os agricultores familiares e outros atores locais possam, mesmo que mínimo, participar na contribuição dos projetos destinadas para suas regiões.

\section{Agricultura familiar e projeto Pasa em Guiné-Bissau}

Este estudo tem como objeto o Projeto de Apoio a Segurança Alimentar (Pasa) no território da Guiné-Bissau, especificamente nas regiões de Biombo, Gabu e Tombali. Guiné-Bissau tem sua base econômica estruturada na agricultura.

O projeto Pasa, assim como muitos que o país conheceu, é esforço do governo na tentativa de criar condições de produção de alimento suficiente para garantir a soberania alimentar. Porém, o esforço nem sempre se coroou de êxito e as dificuldades continuam as mesmas. A partir daí urge a necessidade de se debater os modelos das políticas públicas implementadas no país.

Há um anseio da população guineense, em particular das regiões e das aldeias beneficiadas, pelos resultados do projeto, quanto à melhoria do acesso a alguns serviços e alívio nas crises da produção de alimentos. Este anseio obriga, em sua maioria, os dirigentes ou tomadores de decisões (policymakers) na escolha da estratégia a qual entendem como ideal naquele momento. Em muitos casos, estudos têm mostrado que a escolha mais frequente é a da estratégia de top-downs, e em alguns casos não se tem sucesso nas melhorias pretendidas (NAJAM, 1995; CARVALHO; BARBOSA; SOARES, 2010).

Assim, com muita clareza, explicam a situação nos trabalhos de Najam (1995) e Carvalho, Barbosa e Soares (2010). Ambos corroboram o ponto de vista que considera este tipo de decisões como recheada de interesses políticos e de conflitos e com pouco conhecimento e vontade de atender às necessidades da população local. A Figura 1, apresenta as regiões da Guiné-Bissau. 
Figura 1 - Guiné-Bissau e suas regiões e setores administrativos, 2016

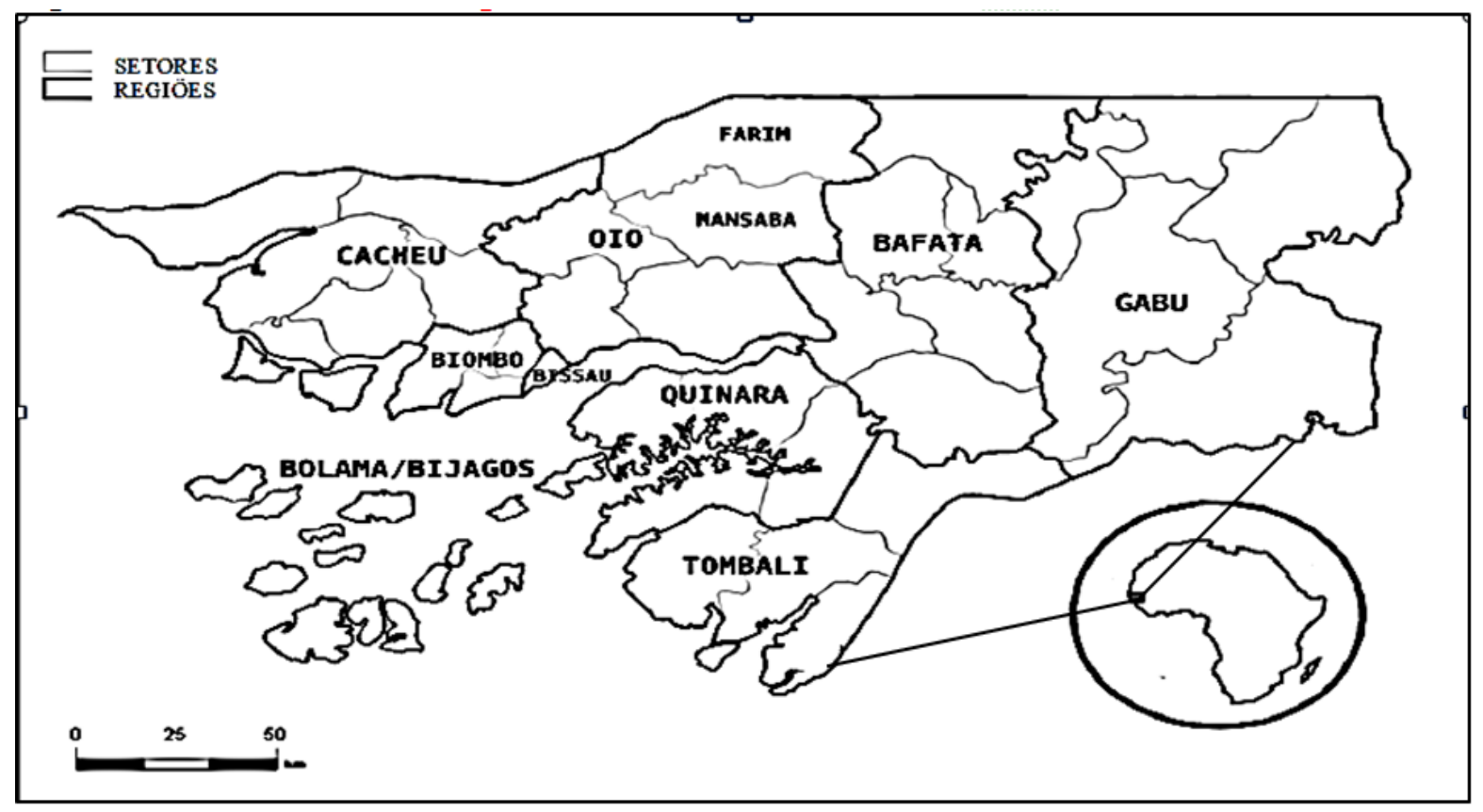

Fonte: Temudo e Abrantes (2014).

O país está localizado na costa Oeste da África e tem uma superfície territorial de $36.125 \mathrm{~km}^{2}$. A população total é de 1,6 milhão de habitantes, sendo que aproximadamente $60 \%$ vive no meio rural. O país é limitado ao Norte por Senegal e a Leste e Sul pela República da Guiné (Guiné-Conakry). A economia do país responde principalmente pelo setor agrícola e a pesca, sendo que a primeira representa 46\% do Produto Interno Bruto (PIB). Por outro lado, a agricultura gera $80 \%$ dos empregos e $90 \%$ das exportações. A castanha de caju é o principal produto de exportação (CATEIA; VELOSO; FEISTEL, 2018).

Cerca de dois terços da população vivem abaixo de linha de pobreza. Adotado de abundantes recursos naturais, o país conta com terras de qualidade e possui um bom índice pluviométrico (de $1500 \mathrm{~mm}$ a $1877 \mathrm{~mm}$, ao ano e chove, em média, 112 dias do ano). O país está dividido administrativamente em oito regiões e 38 setores incluindo o autônomo de Bissau (SOMDA et al., 2004; BIVAR; TEMUDO, 2014; WIGGINS, 2009; PNIA, 2013).

Em todo caso, como já mencionado, é um país predominantemente agrícola, e com foco nas exportações dos produtos da pesca e agricultora. $\mathrm{O}$ olhar fixo nestes dois produtos visa criar uma base de exportação forte que garante o crescimento econômico e a renda dos agricultores (MONTEIRO et al., 2017). North (1995) tem destacado a questão da base econômica das regiões que crescem quando esta mesma base consegue impulsionar novas atividades econômicas no seu espaço doméstico e/ou local. 
O mesmo foi salientado por Piffer (2009), argumentando que o crescimento de uma região, ou seja, o desenvolvimento de uma região, acontece com aumento das atividades de base econômica, que, com isso, impulsionam a demanda dos produtos que esta região produz e oferece para outros mercados fora dos seus limites territoriais.

Porém, North (1955) já argumentava que uma região ou um território jovem apresenta intensa dependência de produtos básicos e é reforçada pelos esforços concentrados dos que no local residem para reduzir os custos de processamento e transferência. Assim, o apoio dos governos que por meio dos subsídios leva a um benefício social geral, também incentiva os fornecedores externos de capital para reinvestirem na base existente. E, à medida que a renda da região cresce, a poupança local tenderá a se espalhar em novos tipos de atividades no seu território.

O território é produzido por atores por meio da energia e da informação, ou seja, da efetivação no espaço. O homem vive relações sociais, construção do território, interações e relações de poder. Este poder é efetivado por diferentes atividades cotidianas, que se revelam na construção de malhas, nós e redes, constituindo seus territórios (SAQUET, 2009). O empoderamento dos territórios de Biombo, Gabu e Tombali, aumenta a interação deste povo com as regiões centrais por meio dos fluxos comerciais, tornando-os atores com poderes de influenciar o desenvolvimento local.

O Pasa, assim como outros projetos iniciados no país depois da independência (1974), tem o objetivo de garantir a segurança, assim como a soberania alimentar. Porém, as incidências de conflitos políticos e a debilidade em geral, dificultaram a integração dos agricultores aos benefícios dos projetos, os quais acabaram não produzindo os frutos esperados e foram abandonados pelo próprio governo. Ainda que, na primeira fase, tenha despertado expectativas positivas, quando continuavam o fluxo do financiamento.

Para North (1955), o desenvolvimento de uma mercadoria para exportação numa região reflete uma vantagem comparativa nos custos de produção, incluindo os custos de transferência deste produto para grandes centros comerciais. Os custos de transferência de distribuição têm servido como elemento limitador à extensão de um mercado para outro, como é o caso das regiões de Biombo, Gabu e Tombali.

O Pasa, assim como outros projetos de desenvolvimento local convivem com seus dilemas de gestão de Estado em benefício da população local. Segundo Dansero, Giaccaria e Governa (2009), o tema "desenvolvimento local" assumiu, progressivamente, a importância central no debate de desenvolvimento do ponto de vista teórico, político e prática operacional da pesquisa. Mas já se passou muito tempo desde se deu o início deste debate, e o desenvolvimento local parece não assumir seu status prático que prometia ocorrer. 
Para Raffestin (1993), o território se forma a partir do espaço e esta formação decorre dos resultados de uma ação conduzida por um autor sintagmático que realiza um programa, cria redes, circuitos e fluxos, e instala as rodovias, canais, estradas e circuitos comerciais. O mesmo autor define o território como um conjunto de relações que se originam num sistema tridimensional e que, ao mesmo tempo, isola, subtrai momentaneamente ou, ainda, manifesta um poder numa área precisa. Assim, estas regiões beneficiadas do projeto Pasa tornam-se, desta forma, grandes espaços de poder, desde que este esforço seja de forma conjunta e com o mínimo das ações impositivas de top-down.

\section{Projeto Pasa como ação top-down}

Guiné-Bissau, como a maioria dos países da África subsaariana, enfrenta enormes dificuldades para conseguir produzir alimento suficiente para alimentar sua população. Por este motivo, o governo do país solicitou, por meio de Ofícios, de 6 de fevereiro e de 5 de maio de 2009, assinados pelo Ministério das Finanças, a criação do Projeto de Apoio a Segurança Alimentar (Pasa). Uma versão inicial desse projeto já havia sido formulada em 2002, apoiada pela Organização das Nações Unidas para a Alimentação e a Agricultura (FAO) e utilizada como projeto piloto que, a partir de então, passava a contar com financiamento do Banco Oeste Africano de Desenvolvimento (BOAD). Assim, em junho de 2010, foi lançado oficialmente o Pasa com previsão inicial de duração de cinco anos, ou seja, de 2010-2015, tendo sido renovado para uma segunda fase de 2015-2020 (PASA, 2012).

O projeto Pasa foi elaborado com objetivo de contribuir para o melhoramento de segurança, assim como a soberania alimentar nas zonas rurais, onde intervém. Seu foco está direcionado, principalmente, para a reabilitação do ordenamento hidroagrícola de mangroves (mangue) e várzeas, com disponibilidade de potencial condição de produção (solos de qualidade e água); também instituir, de maneira intensiva, o sistema de produção diversificada, que melhora as condições de vida da população local; tem a intenção de dinamizar as organizações de produtores, ou seja, transformá-las em atores principais e gestores de desenvolvimento local (PASA, 2012). Pelas características do Projeto, e seguindo a definição do Najam (1995) sobre a iniciativa top-down, torna-se possível afirmar que o Pasa corresponde a este modelo, tal como a maioria dos que foram implementados no país desde 1974.

Ele foi pensado, criado e está sendo gerido pelo governo de Guiné-Bissau por intermédio de Ministério de Agricultura e Desenvolvimento Rural (MADR). O Pasa executa suas atividades com a direção dada por alguns dos quadros alocados no Ministério da Agricultura, conforme pode ser observado na Figura 2, que descreve estrutura das ações do Pasa, para efetivação das suas atividades. 
Figura 2 - Componentes das ações do Pasa na Guiné-Bissau

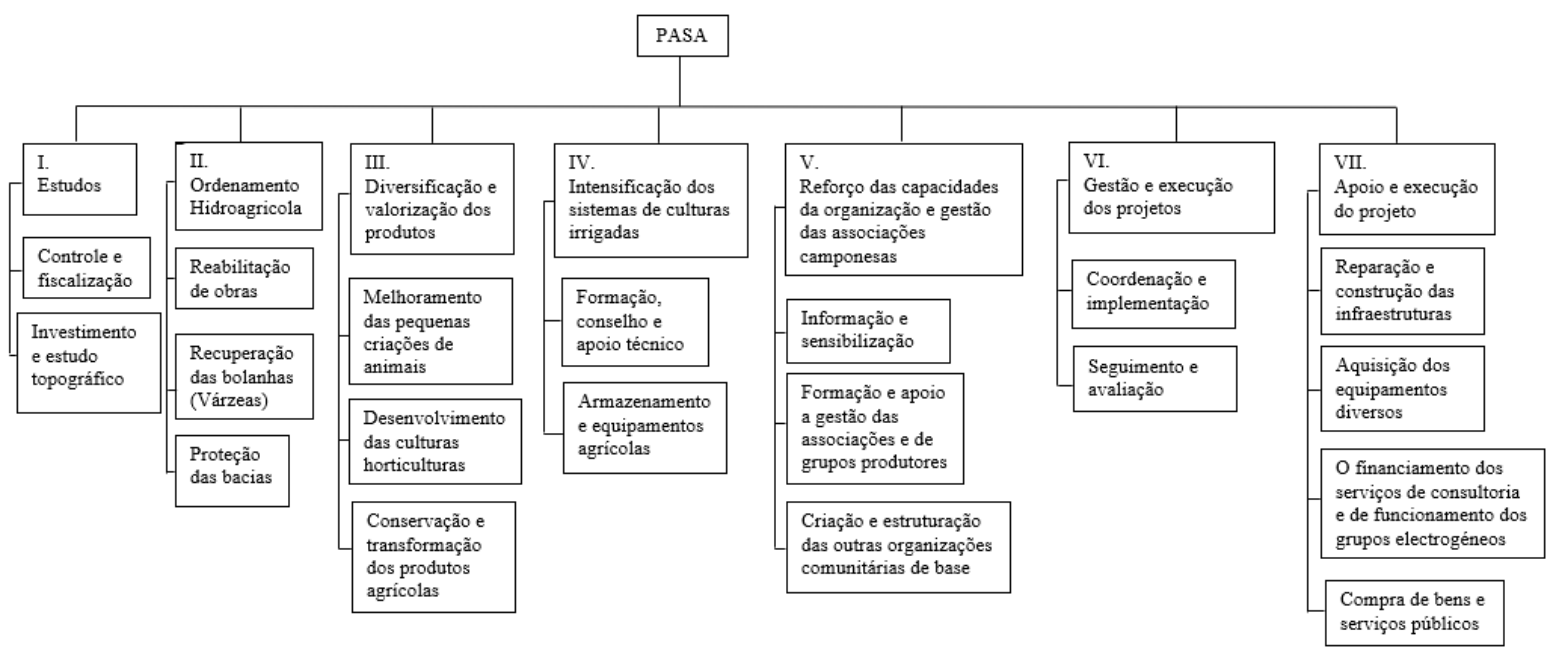

Fonte: elaboração própria a partir de informações do Pasa (2012).

A criação do Pasa expressa a tentativa do governo de atuar sobre alguns dos diversos problemas que a população rural enfrenta. São várias as dificuldades para se manter no campo, para produzir o suficiente de forma diversificada e garantir o consumo anual. As dificuldades forçaram a procura de alternativas, dada a redução de maneira significativa a produção interna de arroz, e procurou-se atender a forte inclinação para a plantação de caju. No relatório de pesquisa realizada pelo Ministério da Agricultura, afirmou-se que, mediante essa alternativa, conseguia-se a reabilitação dos campos de produção de arroz, que aumentou em grande quantidade, o que asseguraria a situação alimentar e faria com que os produtores aproveitassem a renda de caju para a compra de outros bens (GUINÉ-BISSAU, 2012).

Entre estas realizações, ocorreu a formação dos diferentes técnicos ao longo dos anos. Em 2013, participaram cerca de 30 produtores beneficiados da formação nas áreas de gestão de recursos naturais, nos domínios de associativismo e cooperativismo, nutrição animal, gestão de fertilizantes e hidrocarbonetos, manejo de pesticidas, incluindo técnicos da Diretoria Regional do Ministério da Agricultura (GUINÉ-BISSAU, 2013).

O Pasa atua no apoio à segurança alimentar, assim como a soberania alimentar em três regiões: Biombo, Gabu e Tombali (vide Figura 3). Na região de Biombo, o projeto opera nas aldeias de Cupedo e Dorse, que estão situadas a $14 \mathrm{~km}$ da capital regional Quinhamel. Na região de Gabu, o projeto atua nas aldeias de Gã-Cisse, Guidale e Madina Sorri, que estão localizadas no setor de Pirada, a $48 \mathrm{~km}$ da cidade regional Gabu. E, por último, na região de Tombali o projeto está localizado nas aldeias de Catchaque e Cantone, aproximadamente a $13 \mathrm{~km}$ da 
capital regional Catió, denominada de zona agrícola de Catchaque (GUINÉBISSAU, 2012), como pode ser observada no Figura 3.

Figura 3 - Regiões de atuação do projeto Pasa, 2010-2015

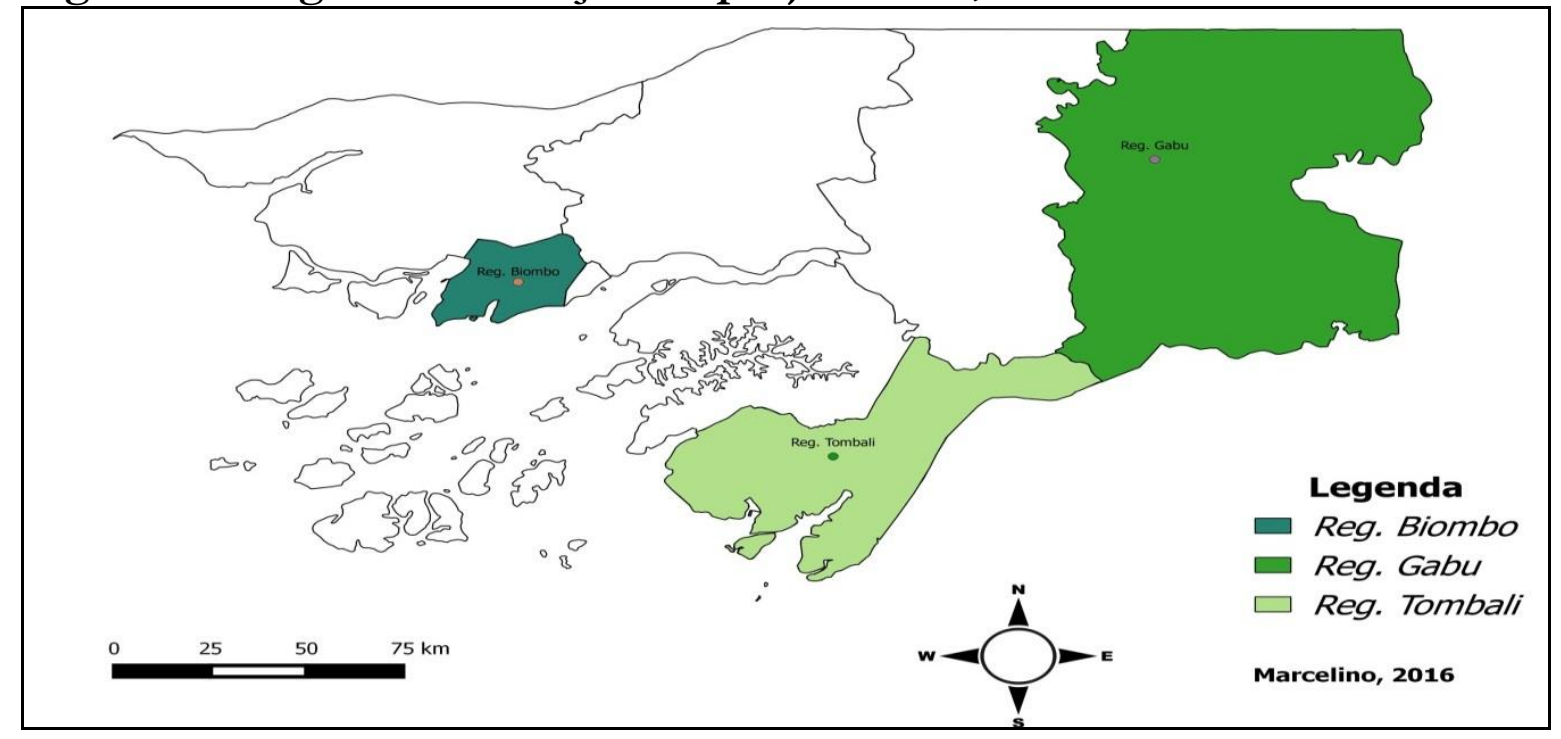

Fonte: elaboração própria, 2016.

Observa-se no mapa que a região de Gabu comporta o maior território entre os contemplados do projeto. A região de Biombo é uma das menores do projeto e está mais próximo da capital do país, Bissau. Também é nesta região onde está localizada a sede administrativo do projeto Pasa, na capital da regional Quinhamel. A região de Tombali é considerada no país como celeiro na produção de arroz (GUINÉ-BISSAU, 2002).

\section{Agricultura familiar e apoio do projeto Pasa}

As caraterísticas das fazendas e a forma da produção familiar em Guiné-Bissau são consideradas como um formato da produção agrícola mais diversificado dos países da sub-região da África Ocidental. As culturas mais frequentes são sorgo, milho, arroz, caju e amendoim. As áreas (propriedades em hectares) destinadas à produção variam em torno de: 1,64 hectares (ha) na produção de sorgo, 1,05 ha na produção de milho, 1,06 ha na produção de arroz e 0,72 ha na de amendoim. São pequenas áreas de culturas, tanto em termos da proporção de plantio quanto de áreas plantadas (SOMDA et al., 2004).

$\mathrm{Na}$ região de Biombo, na aldeia de Cupedo, segundo o Censo de 2009, viviam 871 habitantes, agrupados em 304 famílias. Na aldeia Dorce, estavam 2150 habitantes, com 392 famílias. Dentre essas, somente 34 famílias foram identificadas como 
proprietárias de campos de arroz na aldeia de Cupedo, ou seja, o equivalente a $11,18 \%$. Na aldeia Dorce constatou-se que apenas 8,93\% das famílias eram donas dos campos de arroz (GUINÉ-BISSAU, 2012; INE, 2009), como segue a tabela 1.

\section{Tabela 1 - População de Cupedo e Dorce (Biombo) e sua participação no Pasa}

\begin{tabular}{l|c|c|c|c|c}
\hline \multirow{2}{*}{ Aldeias } & \multirow{2}{*}{$\begin{array}{c}\text { Total de } \\
\text { famílias }\end{array}$} & \multicolumn{2}{|c|}{$\begin{array}{c}\text { Proprietários de } \\
\text { campo de arroz }\end{array}$} & $\begin{array}{c}\text { Membros de família } \\
\text { de proprietários }\end{array}$ & $\begin{array}{c}\text { Famílias que trabalham } \\
\text { no campo do Cupedo }\end{array}$ \\
\cline { 3 - 6 } & & $\mathrm{N}^{\mathrm{o}}$ & $\%$ & $(1)$ & $(2)$ \\
\hline Cupedo & 304 & 24 & 11,18 & 67 & 40 \\
\hline Dorce & 392 & 35 & 8,93 & 57 & 35 \\
\hline Total & 696 & 69 & 20,11 & 124 & 75 \\
\hline
\end{tabular}

Fonte: Guiné-Bissau (2012).

Observações: (1) refere-se aos produtores beneficiados diretos do projeto; (2) refere-se aos produtores beneficiados indiretos do projeto.

Na Tabela 1 se apresenta o grupo de famílias que se dedicam especificamente à atividade agrícola. Em termos de família, como exposto nesta tabela, ele mostra 304 famílias para Cupedo e 392 para Dorce. Assim, no total destas famílias, somente 34 confirmaram que são donos ou proprietários de campo de arroz em Cupedo e 35 em Dorce, que corresponde 9,5\% e 8,5\% dos proprietários nestas aldeias. E neste grupo se totaliza em 69 de proprietários de campo de arroz e outro grupo de 40 famílias que foram recenseados em Cupedo e $35 \mathrm{em}$ Dorce, mas que trabalham no campo de arroz de Cupedo são assim denominados de beneficiados indiretos.

Este último grupo são no total 75 famílias beneficiados indiretamente por projetos, mas que não são objeto de acompanhamento neste período. Os denominados beneficiados diretos são grupos de famílias identificados como proprietários dos campos de arroz. E membros da família dos proprietários, representados na Tabela 1, com o número um (1) serão objetos de acompanhamentos direto do projeto. De tal modo, entre o Cupedo e Dorce são 696 as famílias beneficiadas direta ou indiretamente pelo projeto (GUINÉBISSAU, 2012).

No setor agrícola, as principais dificuldades são: manutenção dos campos de arroz; qualidade de sementes; falta de pesticidas, de equipamentos agrícolas e de terras; e a crescente salinização dos campos de arroz. Estas e outras restrições reduzem, em grande medida, a produção de arroz, mandioca, feijão e produtos hortícolas, que são comercializadas pelas mulheres e cujos rendimentos são utilizados para compensar o déficit de arroz. A atividade de pecuária é muito limitada e se concentra na criação de suínos e caprinos em pequena escala. Na região de 
Tombali, como mostra a tabela 2, a população se defronta com os mesmos problemas.

Tabela 2 - População das cinco aldeias da região de Tombali participantes no projeto

\begin{tabular}{l|c|c|c|c|c}
\hline \multirow{2}{*}{ Aldeias } & $\begin{array}{c}\text { Total de } \\
\text { famílias }\end{array}$ & \multicolumn{2}{|c|}{$\begin{array}{c}\text { Proprietários de campo de } \\
\text { arroz }\end{array}$} & $\begin{array}{c}\text { Membros de } \\
\text { famílias } \\
\text { proprietárias }\end{array}$ & $\begin{array}{c}\text { Novas } \\
\text { famílias nas } \\
\text { aldeias }\end{array}$ \\
\cline { 2 - 6 } & $\mathrm{N}^{\mathrm{o}}$ & $\mathrm{N}^{\mathrm{o}}$ & $\%$ & $(01)$ & $(02)$ \\
\hline Cabaceira & 244 & 19 & 7,78 & 214 & 30 \\
\hline Cubaque & 286 & 35 & 12,24 & 258 & 26 \\
\hline Catchaque & 174 & 31 & 11,49 & 104 & 70 \\
\hline Cantchima & 239 & 23 & 9,62 & 242 & 3 \\
\hline Camaiupa & 379 & 7 & 1,76 & 114 & 265 \\
\hline Cantone & 362 & 36 & 9,9 & 213 & 143 \\
\hline Total & 1322 & 151 & 8,7 & 932 & 394 \\
\hline
\end{tabular}

Fonte: Guiné-Bissau (2012).

Observações: (01) refere-se aos produtores beneficiados diretos do projeto; (02) refere-se aos produtores beneficiados indiretos do projeto.

Na região de Tombali, o Pasa incluiu seis aldeias tal como apresentado na Tabela 2. Diferente do que foi apresentado na Tabela 1, são grupos de aldeias que, em conjunto, somam 1.322 famílias, que se dedicam especificamente à agricultura. A primeira aldeia, a Cabacera, é constituída por 244 famílias; Cubaque por 286; Catchaque por 174; Catchima por 239; Camaiupa por 379; e Cantone por 362. Entre estas famílias, 151 se declararam como proprietárias de campo de arroz, sendo que 19 são de Cabacera, 35 de Cubaque, 31 do Catchaque, 23 de Catchima, 07 de Camaiupa e 36 de Cantone.

O grupo que compõe o total das pessoas nas famílias dos proprietários sinalizados na Tabela 2, na coluna de número 01, são pessoas que fazem parte da família dos que se declararam como proprietários e que são objeto direto da observação do projeto, sendo o total de 932 famílias. E na coluna sinalizada com número 02, diferente do anterior da Tabela 1, está o grupo das famílias que não são e não fazem parte dos que declararam como proprietários de campo de arroz. E nesta região surge um novo grupo de famílias recém-chegadas nas aldeias, assim totalizando 394 famílias. Desse modo, estas aldeias são dependentes do campo de arroz da Zona de Catchuque e também contam com uma segunda atividade produtiva: a pesca artesanal, no interior. A região de Tombali recebeu o título de celeiro do país na produção de cereais, em particular, arroz, desde década de 1960, e continua sendo até hoje (GUINÉ-BISSAU, 2002). 
No final dos anos 1980 surgiu a oportunidade de rendimentos com a produção de caju. Esta atividade emergiu entre as que ganharam terreno como atividade secundária (madeira, carvão, óleo de palma etc.) e pecuária dos pequenos ruminantes. No entanto, a região de Tombali é uma das que mais sofre com problemas de acesso devido ao estado caótico das estradas, o que não motiva a presença dos funcionários públicos e atrapalha a comercialização dos produtos (PASA, 2010).

A tabela 3 apresenta o grupo de famílias da região de Gabu, cuja principal cultivo é o arroz em sistema de várzeas. Também consta neste grupo de aldeias a categoria de famílias não agrícolas, mesmo residindo neste ambiente onde a atividade mais comum é agricultura. Nesta região vive um grupo étnico habituado com práticas de pastoril e de pequeno comércio de ambulantes.

Tabela 3 - Distribuição dos produtores de arroz de várzeas da região de Gabu

\begin{tabular}{l|c|c|c}
\hline Aldeias & Total da População & $\begin{array}{c}\text { Proprietários de } \\
\text { capo de arroz }\end{array}$ & $\begin{array}{c}\text { Os que vivem da } \\
\text { atividade não-agrícola }\end{array}$ \\
\hline Gancisse & 574 & 85 & 489 \\
\hline Guida & 209 & 51 & 158 \\
\hline Madina Sorri & 417 & 208 & 209 \\
\hline Sedjo-Madina & 456 & 215 & 241 \\
\hline Sedjo Fula & 102 & 43 & 59 \\
\hline Sedjo Mandinga & 456 & 136 & 320 \\
\hline Total & 2.214 & 738 & 1.476 \\
\hline
\end{tabular}

Fonte: Guiné-Bissau (2012).

A produção de arroz ocorre no sistema várzeas, e as propriedades são menores, a semelhança do milho, feijão, amendoim etc. Há, no entanto, cerca de 200 mil hectares de campo de arroz de várzeas que atendem às condições de produção e permitem à população se desenvolver, mesmo com limitações.

As atividades previstas na primeira fase do Pasa, principalmente a implementação de controle da água nos campos de arroz, foram concluídas. O projeto construiu $11 \mathrm{~km}$ de pistas rurais, das quais cinco foram na região de Tombali que a conectou com a aldeia de Catchaque. Os outros 20 ha de áreas de produção de hortaliças foram distribuídos e construídos seis armazéns com câmaras de estocagem para o arroz e outros produtos secos. O Pasa conseguiu fazer com que os produtores alcançassem um incremento anual na produção 4.000 toneladas de arroz (com casca) e 1.000 toneladas de produtos hortícolas. Houve também o incremento de 690 toneladas de produção animal e 50 grupos dos produtores foram formados 
em diferentes áreas: contabilidade, gestão das cooperativas, técnico agrícola, gestão de crédito, gestão de água etc. Foram criadas as possibilidades de acesso a crédito de insumos, equipamentos e comercialização.

Também foram alfabetizadas 200 pessoas nas três regiões de atuação do projeto e foi possível a elaboração do programa de alfabetização para outras regiões. Foram formalizadas 17 associações iniciadas em 2012 e apoiada a criação de mais 27 novas associações locais, além da constituição de quatro grupos de intervenção econômica e financeira nas áreas de atuação.

\section{Considerações finais}

O objetivo deste artigo foi analisar no âmbito teórico os resultados do Projeto de Apoio a Segurança Alimentar (Pasa) nas regiões onde atua na sua primeira fase nos períodos de 2010-2015, aos agricultores e as aldeias beneficiadas. Como pode se constatar, as poucas informações que dispomos levam a entender que a primeira fase cumpriu seus objetivos e metas. O ordenamento do território rural de mangrove (mangue) e de várzeas e recuperação de alguns campos de produção de arroz que já estavam em situação de abandono, iniciados nos projetos de rizicultura dos anos de 1980.

Também a atuação do projeto tornou fácil o escoamento dos produtos, devido à construção de vias rurais nas regiões de Gabu e Tombali. Isso permite o dinamismo em diversas ações socioeconômico e mobilidade das pessoas que vivem nestas aldeias. O controle e recuperação dos campos afetados pela água salgada e novos campos para as famílias que não dispunham de espaço para produção. Estas ações, do Pasa tem outra face importante, além de criação de emprego, também servem de condicionante para manter esta população nas suas aldeias mesmo de forma um pouco oscilante.

Outros benefícios importantes levados pelo projeto são ações ligadas à formação em diferentes áreas do mundo rural, algumas delas com enfoque essencialmente nos trabalhos ligadas às áreas urbanas, como contabilidade e gestão. $\mathrm{O}$ apoio da criação e capacitação dos agricultores nos domínios de associativismo e cooperativismo incide, sobretudo, no papel do Estado ou governo na criação das capacidades dos atores que poderão atuar no dinamismo das ações de transformação local no futuro.

Mas, como a maioria dos agricultores são analfabetos, o Pasa reconheceu a situação e reformulou o acordo com a Direção Geral de Alfabetização, para formar os agricultores que futuramente serão capazes de melhorarem suas produções e se integrarem melhor no mercado. Também os trabalhos da produção de hortaliças praticada principalmente pelas mulheres nos arredores das cidades foram ampliados. 
O que se pode considerar neste processo inicial do projeto Pasa é o seu caráter essencialmente governamental, que idealizou, planejou e serve como o executor. Ficam claras suas caraterísticas de estratégias de top-down, mesmo com ações que tentam integrar os produtores. Porém, as ações aplicadas não surgiram das discussões e sugestões dos agricultores locais com necessidade urgente. Como bem mostrou Najam (1995) e Teixeira (2001), estes tipos de estratégias podem aliviar inicialmente os problemas, mas não são, em sua maioria, adequadas às necessidades dos beneficiados e, portanto, poucos prosperam.

Outra indicação importante alinhada com os autores é o não entendimento dos beneficiados dos projetos de alguns sinais de intenção dos planejadores: não sabendo o que seus governantes desejam, eles não conseguem fazer o que seus projetos querem, ou eles recusam em fazer o que os idealizadores do projeto intencionam. Este desencontro dos objetivos permite afirmar ser essa uma das causas que levaram muitos projetos de desenvolvimento rural do país, desde os primeiros anos da independência, a não se continuarem em atividade. Há de se concordar com o desempenho de Pasa no momento. A capacidade de fazer a população desacreditada nos projetos descontinuados anteriormente se envolver ativamente nos projetos e ações lançados atualmente.

Enfim, o Pasa conseguiu realizar alguns dos seus objetivos, tais como reordenamento e postos em atividades nas terras que anteriormente foram afetadas pela água salgada; construção ou reconstrução das vias de acesso das aldeias com o mercado regional; fortalecimento da associação ou criação das cooperativas dos produtores locais; criação dos mecanismos de acesso local do sistema de crédito (inclusão financeira) e construção dos armazéns locais para conservação dos produtos. Mas, algumas ações ainda faltam para serem efetuadas como: melhoria da capacidade produtiva (quanto aos insumos, equipamentos e melhora na cadeia produtiva), quantidade e qualidade de tipos de linhas de crédito oferecidos, integrar estas aldeias com as regiões e, por conseguinte com os maiores centros de comércio do país.

\section{Referências}

ARAÚJO, M. Safety e security: conceitos diferentes. Segurança e Qualidade Alimentar, n. 3, nov. 2007, p. 1-61.

APESS-ASSOCIATION POUR LA PROMOTION DE L'ELEVAGE AU SAHEL ET EN SAVANE. Profils d'exploitations familiales d'éleveurs en Afrique de l'Ouest et em Afrique Centrale: Loïc Barbedette Sociologue, Juil. 2013. 
BARON, C. Mutations institutionnelles setre compositions des territoires urbainsen Afrique: une analyse à travers la problématique de l'accès à l'eau. Réseau: Développement durable et territoires, Dossier 6, 2006.

BELIK, W. Desenvolvimento territorial e soberania alimentar. In: ALMEIDA FILHO, Niemeyer; RAMOS, Pedro (Org.) Segurança alimentar: produção agrícola e desenvolvimento territorial. Campinas: Alínea, 2010, p. 169-192.

BIVAR, M.; TEMUDO, M. P. Rice, cows and envy: agriculture and change among young rice producers in Guinea-Bissau. Working Paper 086, Abr. 2014.

CARVAlHO, M. de L. de; BARBOSA, T. da C. G.; SOARES, J. B. Implementação de política pública: uma abordagem teórica e crítica. In: Anais do X Coloquio Internacional sobre Gestión Universitaria en América del Sur. Mar del Plata, Dez. 2010.

CATEIA, J. V.; VELOSO, G. de O.; FEISTEL, P. R. Castanha de caju da GuinéBissau (1986-2011): uma análise sob a ótica do modelo de gravidade de Bergstrand. RESR, Piracicaba, 56 (4), p. 583-604, Out./Dez. 2018.

DANSERO, E.; GIACCARIA, P.; GOVERNA, F. O desenvolvimento local: contextos nacionais em confronto. In: SAQUET, M. A.; SPOSITO, E. S. (Org.) Territórios e territorialidades: teorias, processos e conflitos. São Paulo: Expressão Popular: UNESP-Programa de Pós-Graduação em Geografia, 2009, p. 249-269.

DRECHSEL, P.; COFIE, O. O.; VEENHUIZEN, R. V.; LARBI, T. O. Linking research, capacity building, and policy dialogue in support of informal irrigation in urban West Africa. Irrigation and Drainage, n. 57, 2008, p. 268-278.

ECOWAS-ECONOMIC COMMUNITY OF WEST AFRICAN STATES. Regional agricultural policy for West Africa: ECOWAP. ECOWAS Commission: Abuja, Jun. 2008.

EDWARDS, G. C. Implementing public policy. Washington/DC: Congressional Quarterly Press, 1980.

FONSECA F. Dimensões críticas das políticas públicas. Cadernos EBAPE.BR, v. 11, n. 3, Rio de Janeiro, Set./Nov. 2013, p. 402-418.

GIL, António Carlos. Métodos e técnicas de pesquisa social. 6 ed. São Paulo: Atlas, 2008. 
GUINÉ-BISSAU. Ministere Agriculture et du Developpement Rural. Composant Environnemental et Social. Rapport d'Ativicté. Quinhamel, Jan. 2013.

GUINÉ-BISSAU. Ministere Agriculture et du Developpement Rural. Rapport Final D’etude Socio-Economique. Quinhamel, Set. 2012.

GUINÉ-BISSAU. Ministere Agriculture et du Developpement Rural. Carta de política de desenvolvimento agrário. Bissau: MAFP, Abr. 2002.

LINDER, S. H.; PETER, B. G. A design perspective on policy implementation: the fallacies of misplaced prescription. Policy Studies Review, 1987.

MATSHE, Innocent. Boosting smallholder production for food security: some approaches and evidence from studies in Sub-Saharan Africa. Agrekon, v. 48, n. 4, Dez. 2009, p. 483-511.

MAZMANIA, D. A.; SABATIER, P. A. Introdution: in effective policy implementation. Lexington Books, 1983.

MONTEIRO, J. V. Um padrão de política pública na crise econômica mundial. Revista de Administração Pública, Rio de Janeiro, Nov./Dez. 2008.

MONTEIRO, A. M. et al. Custo de transação e dinâmica das instituiç,ões no mercado de caju na Guiné-Bissau. In: Anais do VIII Seminário Internacional sobro Territórios, Redes e Desenvolvimento Regional: perspectivas e desafios Santa Cruz do Sul/RS, 13-15 Set. 2017.

NAJAM, A. Learning from the literature on policy implementation: a synthesis perspective. IIASA Working Paper. Laxenburg/Austria: IIASA, 1995.

NORTH, D. C. Location theory and regional economic growth. Journal of Political Economy, v. 63, Jun. 1955, p. 243-258.

PEREIRA A. P. Políticas sociais: temas \& questões. 2 ed. São Paulo: Cortez, 2008.

PIFFER, M. A teoria da base econômica e o desenvolvimento regional do Estado do Paraná no final do século XX. 167f. Tese (Doutorado em Desenvolvimento Regional) - Universidade de Santa Cruz do Sul, Santa Cruz do Sul, 2009.

PNIA - Programa Nacional de Investimento Agrícola: plano de investimento. Bissau, Nov. 2013. 
PASA-PROJET D’APPUI À LA SECURRITÉ ALIMENTAIRE. Plan de travail et budget annuel - 2013. Quinhamel, Jan./Dez. 2013.

PASA-PROJET D'APPUI À LA SECURRITÉ ALIMENTAIRE. Composant II: aménagements hydroagricoles (CAHA) (= Rapport d'Activités, 2012). Quinhamel, Dez. 2012.

PASA-PROJET D'APPUI À LA SECURRITÉ ALIMENTAIRE. Etude d'impact environnemental et social. Rapport Provisoire. Quinhamel, Set. 2010.

RAFFESTIN, C. Por uma geografia do poder. São Paulo: Ática, 1993.

INE-Instituto Nacional de Estatística. Recenciamento geral da população e habitação (= RGPH, 2009). Bissau: Ministério de Economia e Integração Regional, 2009.

SAQUET, M. A. Por uma abordagem territorial. In: SAQUET, M. A.; SPOSITO, E. S. (Org.) Territórios e territorialidades: teorias, processos e conflitos. São Paulo: Expressão Popular: UNESP: Programa de Pós-Graduação em Geografia, 2009, p. 73-94.

SOMDA, Jacques; KAMUANGA, Mulumba; MÜNSTERMANN, Susanne; KEITA, Kelefa; MENDES, Antônio. Characteristics of the smallholder dairying farmers in West African countries: economic viability and paths for improvement (= Socio-Economic Research Working Paper, n. 2). Banjul: ITC, 2004.

SOUZA, C. Políticas públicas: uma revisão da literatura. Sociologias, Porto Alegre, 8 (16), Jul./Dez. 2006, p. 20-45.

TEIXEIRA, E. C. O local e o global: limites e desafios da participação cidadã. São Paulo: Cortez, 2001.

TEMUDO, M. P.; ABRANTES, M. The cashew frontier in Guinea-Bissau, West Africa: changing landscapes and livelihoods. Human Ecology, 42 (2), Feb. 2014, p. 217-230.

WIGGINS, Steve. Can the smallholder model deliver poverty reduction and food security for a rapidly growing population in Africa? In: FAO expert meeting on "How to feed the World in 2050", 24-26 Jun. 2009, p. 1- 20. 
VAN METER, D. S.; VAN HORM, C. E. The policy implementation process. Administration and Society, 6 (4), 1975.

VENDRAMINI, A. L. do A.; OLIVEIRA, J. C. de; CAMPI, M. A. Segurança alimentar: conceito, parâmetros e história. In: Anais do Congresso Internacional Interdisciplinar em Sociais e Humanidades. Niterói/RJ: ANINTER-SH/ PPGSD-UFF, 03 a 06 de setembro de 2012.

Endereço para correspondência:

Marcelino Armindo Monteiro - yuorna@gmail.com

Rua da Faculdade, 645 - Jardim Santa Maria 85903-000 Toledo/PR, Brasil

Zelimar Soares Bidarra-zelimar@1yahoo.com.br Rua da Faculdade, 645 - Jardim Santa Maria 85903-000 Toledo/PR, Brasil

MoacirPiffer-mopiffer@1yahoo.com.br Rua da Faculdade, 645 - Jardim Santa Maria 85903-000 Toledo/PR, Brasil 
Marcelino Armindo Monteiro, Zelimar Soares Bidarra e Moacir Piffer

78| Revista Brasileira de Desenvolvimento Regional, Blumenau, 8 (2), P. 55-78, 2020 